\title{
The Digitalization Index: Developing a Model for Assessing the Degree of Digitalization of Construction Projects
}

\author{
Ahmet Anil Sezer ${ }^{1}$, Micael Thunberg ${ }^{2}$, Brian Wernicke ${ }^{3}$ \\ ${ }^{1} \mathrm{Ph} . D$., Linköping University, Department of Science and Technology, SE-601 74, Norrköping, \\ Sweden (corresponding author). E-mail: ahmet.sezer@liu.se \\ ${ }^{2} \mathrm{Ph} . D$., Linköping University, Department of Science and Technology, SE-601 74, Norrköping, \\ Sweden. \\ ${ }^{3}$ Ph.D., Luleå University of Technology, Department of Civil, Environmental and Natural \\ Resources Engineering, SE-97 187, Luleå, Sweden.
}

\section{Abstract}

The construction industry is one of the least digitally advanced industries. Although the industry is project based, a project level assessment of digitalization is lacking. The aim of this paper is to develop a digitalization index to assess the degree of digitalization of construction projects. Relying on the outcomes of a workshop with 11 participants and questionnaire responses from 113 site managers in Sweden, four activities, visualizing drawings and 3-D models on sites, updating drawings, models and system documents, creating and updating work disposition plans, and updating time resource plans were selected and a digitalization index enabling a simple assessment of the degree of digitalization of construction projects was constructed based on the degree of digitalization of the data management processes involved in these four activities. The approach to determining the digitalization index was demonstrated on a case study of a new construction project. For future studies, an accurate and simple assessment of degree of digitalization of projects should increase the opportunities to study the association between degree of digitalization and project performance. With longitudinal assessments, digitalization trends in the construction industry can be reported.

Key words: Construction management, Construction site, Digitalization, and Digitalization index. 


\section{Introduction}

There is no doubt that we are living in an era of digitalization. Processing and manufacturing companies are experiencing digitalization in line with industry 4.0, which is allowing the use of concepts like Internet of Things and automation to improve productivity and safety but also to reduce the environmental impact (Hasan et al. 2018). The construction industry is part of this digital transformation and many new technologies are being introduced by technology suppliers and construction firms. These include building information modelling (BIM), big data, cloud storage, multidimensional design (e.g. 4D, 5D), pre-fabrication, robotics, 3D printing, artificial intelligence and intelligent buildings (Sykes 2018). Nevertheless, the construction industry is considered one of the least digitally advanced industries in terms of its digital assets, digital usage and digital workforce engagement and is ranked joint last with agriculture and hunting in a list of 22 industries (Gandhi et al. 2016). However, the tools (and models) used to assess the “degree of digitalization" are associated with inherent design flaws.

Previous work has focused mainly on assessing digitalization at the industry and company levels. At the industry level, there are many examples of industry reports and academic studies comparing levels of digitalization (e.g. Gandhi et al. (2016); Gruszka et al. (2017); Schober et al. (2016); Sykes (2018)). Other work uses industry level surveys to show which technologies are being used and in which areas in construction projects (Blanco et al. 2017; Samuelson and Björk 2014). In addition, the construction industry is decentralized, fragmented and project based which results in contracting firms operating more as ecosystems working on autonomous projects. Comparing the ongoing projects in a contractor firm in terms of their digitalization would help to identify where digitalization might lead to improvements (Sezer and Bröchner 2019). 
A project level assessment of the degree of digitalization is lacking and company and industry level models are too "blunt" to facilitate actions to improve digitalization. Before discussing the existing attempts to improve digitalization in the construction industry, we need first to assess the degree of digitalization at the project level to allow identification of the problems. Project rankings based on degree of digitalization can help to identify best practice. Therefore, the aim of this paper is to develop a digitalization index to assess degree of digitalization of construction projects.

There are few examples of project level assessment models. A pioneering study by O'Connor et al. (1999) proposed the technology use and integration index (TUI) which is based on three levels of technology use for 68 tasks. Reporting the degree of digitalization for so many activities is time consuming and exhausting and becomes an even bigger problem if the assessor is the site manager. "Lack of time" is a frequent reason given by site managers for not engaging in this activity (Sezer and Bröchner 2019). A simpler index to assess degree of digitalization of projects is necessary. This index and its outcomes can make it feasible for researchers to compare projects with different degrees of digitalization to identify their differences and associate levels of digitalization with productivity, safety and environmental performance. In practice, construction companies can identify projects with high and low levels of digitalization in order to try to improve the latter.

The paper is organized as follows. Next section presents previous work assessing the degree of digitalization and technology implementation to provide a better understanding of the pros and cons of these earlier models. This is followed by a section describing the research design and a section presenting the proposed assessment model. The final section concludes the paper and proposes some directions for future research and some theoretical and practical implications. 


\section{Previous Research}

Previous studies include assessments of use of information technology (IT) and information and communication technologies (ICT) in the construction industry, the digital maturity of construction companies and technology usage and integration indexes at the project level. Most of this work provides a snapshot of digitalization in the industry. The IT-barometer developed by Samuelson (2002) is used to assesses the construction industry's usage of IT tools including perspective of architects, engineers, property managers and contractors. The IT-barometer is used to assess the extent of IT infrastructure and work that is carried out with the help of computers, digital information exchange, BIM usage, computer aided design (CAD) usage, electronic document management and electronic document interchange usage. The ITbarometer is also used to understand the effects of and motives for using IT, the perceived benefits and disadvantages of using IT, and planned IT investments (Samuelson and Björk 2014). IT-barometer surveys have been applied in several different countries including Luxembourg (Kubicki and Boton 2014) and Jordan (El-Mashaleh 2007). Other work at the industry level investigates use of computers, IT and automated devices by construction workers, and the views of construction workers, managers and technology providers in Alberta, Canada (Hewage et al. 2008). The literature includes comparisons of IT adoption by 20 developing and developed countries (Nourbakhsh et al. 2012), IT use by construction professionals such as architects, consultants and contractors (Shrestha et al. 2011), ICT use by Swedish site managers (Sezer and Bröchner 2019), IT use in Malaysian (Gaith et al. 2009) and Nigerian (Serpell et al. 2005) construction industries and ICT use in the Turkish construction industry (Sarshar and Isikdag 2004).

At the company level, digital maturity is a frequently used term. An example of assessing digital maturity of construction companies is a recent online platform (Letsbuild 2020), which is based on people, processes, data and technology and provides a seven-level ranking based on: 
business as usual, present and active, formalized, strategic, converged, innovative and adaptive and, guiding star. Other company level examples not focused specifically on the construction industry include a simple, single measure of digital maturity called the digital quotient (Catlin et al. 2015), which examines such aspects as strategy, capabilities, culture and organization, and talent.

At the project level, there are previous examples which use terms such as technology use and integration (TUI) index and automation and integration scales. O'Connor et al. (1999) develop automation and integration measures based on three levels of technology use, Yang (2008) uses four levels to assess the degree of automation and Kang et al. (2008) define levels of technology use based on the categories of "automation technology" and "integration technology" with each involving assessment at five levels. The levels they describe are based on a scale where tasks are carried out manually to tasks being carried out automated, where Level 1 includes no electronic tools to complete a work function, level 2 includes some use of electronic tools and level 3 is fully automated systems to perform the work function. These assessment levels have been used in other studies to investigate the relations between technology use and various outcomes including the relation between project performance and technology use at the project phase and project levels (O'Connor and Yang 2004) and project stakeholder success (Yang and O'Connor 2005), and to compare different sized projects and the effects of technology use on costs and schedules (Yang et al. 2006) in the US and Taiwan contexts (Yang et al. 2007).

Based on the literature, it can be concluded that there is a greater focus on assessing digitalization at the industry and company levels than at a project level. However, the construction industry is project-based, and the company and industry level models are not sufficiently fine grained to identify where greater digitalization would provide benefits. One of the limitations of previous attempts to measure digitalization in construction projects is that they require assessment of degree of technology use for more than 50 activities which is 
cumbersome. The assessments and the levels are rather abstract, meaning that a task supported by technology could involve different levels such as inputting data or analyzing and reporting data. Frequency tends to be overlooked and a technology is not necessarily used always at the highest degree of technology use (e.g. always at Level 3), but rather a combination of different degrees in different frequencies (e.g. rarely at Level 1 and often at Level 2). A clear takeaway from previous studies is that a simpler and less exhaustive project level digitalization index is needed to allow the benchmarking of degree of digitalization in projects.

\section{Research Design}

The research design includes a literature review to identify construction site activities. This resulted in a list of 27 activities. To reduce the number of activities included in the assessment model, a workshop and questionnaire study were organized. The final model was based on the results of these steps.

\section{Literature Review}

The aim of the literature review was to identify construction site activities which was based on keyword searches and previous studies e.g. (Samuelson 2002; Samuelson 2008; Samuelson and Björk 2014). This also included forward and backward citations method (Hu et al. 2011) to add relevant publications. By removing duplicates (e.g. "assigning tasks on construction sites" is removed since it is already covered as "create, prioritize and assign tasks to craftsmen") and merging similar activities (e.g. "registration of waste volumes", "registration of waste sorted on-site", and "waste reuse and recycling systems" are merged as "follow up and improve waste management during the project"), a list with 27 activities was created.

\section{Workshop Design}

To reduce this list of activities to a more manageable number we conducted a three-hour workshop involving 11 participants (not including the workshop organizers). We sent the 
invitation to 209 individuals who were members of a Swedish organization interested in construction logistics and digitalization. It includes actors from different parts of the construction supply chain and the construction industry. The eleven workshop participants represented a range of actors including clients, IT-suppliers, contractors, consultants, shipping agencies, academics and plumbing and ventilation subcontractors.

The participants were split across two groups which were asked to define and discuss which construction activities should be digitalized and why. Participants' reasons for identifying particular activities included "which activities are useful to digitalize", "which activities are easy to digitalize", "for which activities digitalization would support links to clients and subcontractors" and "for which activities employees are able to use the technology and have access to hardware". Their selection criteria were similar to the unified theory of acceptance and use of technology (UTAUT) (Venkatesh et al. 2003).

According to the UTAUT, there are four constructs which determine acceptance and use of technology: performance expectancy (usefulness), effort expectancy (ease of use), social influence, and facilitating conditions. Based on the UTAUT constructs, all activities fulfilling these four conditions should already be digitalized and therefore can be used to assess the degree of digitalization of construction projects:

- The activity is useful to digitalize (performance expectancy)

- The activity is easy to digitalize (effort expectancy)

- There are pressures from different stakeholder to digitalize the activity (social influence)

- There are facilitating conditions (such as organizational support, education and ITinfrastructure) to digitalize the activity. 


\section{Questionnaire Design}

The study also involved a questionnaire to reduce the 27 activities. The survey was administered to site managers who have the best understanding of on-site operational work and a good understanding of the daily work activities performed by different actors (Sezer and Bröchner 2019). Thus, we assumed that site managers would be able to identify those activities which are useful and easy to digitalize, activities where there is pressure for them to be digitalized and activities where digitalization is feasible based on workers' capabilities.

The list of site managers was compiled using LinkedIn which has been used by earlier studies (e.g. Ahmad et al. 2018; Kubicki et al. 2019). A search was made to identify site managers in Sweden using alternative Swedish titles including "platschef" and "produktionschef" (both refer to site managers). All the LinkedIn profiles were checked to eliminate site managers not working on new construction and renovation projects (e.g. infrastructure). According to a construction market research company, three of the largest contractors in Sweden had 881 active projects in 2018, where only half of these projects were new construction and renovation projects (Byggfakta, 2018). Therefore, the whole population of new construction and renovation site managers are expected to be relatively small in Sweden. The questionnaire and two reminders were sent to a total of 350 Swedish site managers. We received 83 complete responses, and 30 partial responses to the first part of the questionnaire. This translates into a response rate of $32 \%$. Response rates for these kinds of questionnaires can vary between $12 \%$ and 40\% (Ahuja et al. 2010; Chalker and Loosemore 2016; Samuelson and Björk 2014; Sezer and Bröchner 2019). Chalker and Loosemore (2016) explain low response rates in the construction industry as due to high workloads and site managers are often forced to prioritize construction site tasks. Sezer and Bröchner (2019) attempted to increase the response rate by combining an online and a postal survey of site managers but achieved only a $34 \%$ response rate. 
The questionnaire design was based on the UTAUT. It started with questions about gender, age, experience, firm size and type of construction projects that were most frequent in the last 5 years. The main part of the questionnaire was organized in four parts:

- Usefulness of digitalizing an activity (performance expectancy) - digitalization allowed faster task performance and increased productivity compared to traditional working,

- $\quad$ simplicity (effort expectancy) - digitalization would be easy to implement, use and learn compared to traditional ways of working,

- pressure for digitalization (social influence) - whether customers, subcontractors, suppliers or other firm members (colleagues, management, etc.) were pushing for digitalization of some activities,

- conditions for digitalization (facilitating conditions) - whether organizational knowledge and the technical infrastructure (including training and support) required for digitalization were in place.

Respondents were asked to indicate any activities which they felt should have been included in the original 27. Only two respondents suggested additional activities. The respondents were asked to select 5 activities from the list of 27 activities and rank them on a scale from 1 to 5 based on the above conditions (e.g. 5 indicates - most useful to digitalize and 1 least useful to digitalize).

Table 1 presents respondent demographics. The majority (91\%) were male and three were aged over 61 years. All had at least 3 years of experience in the construction industry, and most $(80 \%)$ had more than 10 years of experience. Only $20 \%$ of respondents reported having worked on renovation projects $(n=23)$. Most were from larger contractors $(83 \%)$ with at least 250 employees. 
Table 1. Respondent demographics

$<$ Insert Table 1 here $>$

Questionnaire analysis includes descriptive statistics and non-parametric Mann-Whitney and Kruskal-Wallis tests. The four main parts of the questionnaire (i) usefulness, (ii) ease of use, (iii) pressure of digitalization and (iv) facilitating conditions received 113, 92, 84 and 83 responses respectively. The sum of the rankings of the 27 activities in each part were normalized. Summing the normalized values, we identified five highly ranked activities. MannWhitney and Kruskal-Wallis tests were employed to ensure that subgroups of site managers with different gender, years of experience, types of project experience and employed in different sized of companies did not rank these activities differently. The Kruskal-Wallis test allows comparison of multiple independent groups; the Mann-Whitney test allows comparison of two independent groups (Pett 2015). Here the Kruskal-Wallis tests checked whether site managers in different age groups valued these five activities differently, and the Mann-Whitney test checks whether site managers of different gender, with different numbers of years of experience, working in different types of projects and employed by different sized of companies saw these five activities differently. The small sample sizes in certain groups (e.g. only 10 female respondents) should not be a problem, considering that non-parametric tests including Mann-Whitney are appropriate even with very small sample sizes (Pett, 2015).

\section{Model Creation}

To construct the model to assess digitalization of the activities based on the questionnaire responses, first, we examined how the technology was used in a construction site activity, and second, we examined data management processes involved. After identifying the data management processes employed, the degree of digitalization of each of them were examined. Data management processes may involve different degrees of digitalization; they may be 
combined and used to different degrees and at different frequencies. We then examined with what frequency was this degree of digitalization exploited. Keywords were used to search the literature and the snowballing technique was used. After interrogating the literature to address the first question, new searches were conducted to address all the other issues in turn.

\section{Developing a model to assess the degree of digitalization}

\section{Activities identified to digitalize}

Full list of activities based on the literature review

The full list included 27 activities with potential for digitalization (see Table 2 which also provides information on the source of the information).

\section{Ranking of activities}

The next step involved identifying which activities were useful and easy to digitalize, had higher pressure and the best facilitating conditions to be digitalized.

Table 2. Gross list of potential activities to digitalize.

$<$ Insert Table 2 here $>$

The respondent data was normalized, as described earlier, each part (usefulness, ease, pressure and facilitating conditions) had different numbers of responses. The next step in the analysis to identify activities was to calculate a total "digitalization need" value for each activity. This was done by summarizing the $1-5$ rankings for usefulness $(U)$, ease $(E)$, pressure $(P)$, and facilitating conditions (C) of all the respondents (n) for each activity (x), see equation (1).

$$
\operatorname{Total}_{x}=\sum_{i=1}^{n} U_{x, i}+E_{x, i}+P_{x, i}+F_{x, i} \quad \forall x=1, \ldots, 27
$$


Table 3 presents total values for all 27 activities and shows that the top five activities which should already be digitalized in construction projects are, visualize drawings and 3-D models on site; update drawings, models and system documents; update of time and resource plans; create and update work disposition plans and; keeping site diaries.

To ensure that subgroups such as male groups and female groups of site managers did not rank these activities differently, we applied Mann-Whitney and Kruskal-Wallis tests. The MannWhitney test showed that different gender, different years of experience, different types of projects and employment in companies of different sizes had no significant effect on opinions related to the five activities mentioned above (at $\mathrm{p}<0.05$ level). The Kruskal-Wallis test checked whether site managers in different age groups had different opinions of the five activities; we found no significance (at $\mathrm{p}<0.05$ level). However, when subgroup rankings were compared, we found that four of the above activities were always in the top five, but "keeping site diaries" was excluded from the top 5 activities for 9 of the subgroups (e.g. ranked $7^{\text {th }}$ by site managers working in large contractors and $6^{\text {th }}$ by female site managers). Therefore, only four activities were selected: visualize drawings and 3-D models on sites; update drawings, models and system documents; create and update work disposition plans; and update of time and resource plans. The next step in the process involves identifying a method of assessment of the degree of digitalization of the four identified activities.

Table 3. Normalized sum of ranks of 27 activities ( $U=$ usefulness, $E=$ ease of use, $P=$ peer pressure and $\mathrm{C}=$ facilitating conditions).

$<$ Insert Table 3 here $>$

\section{Assessing the degree of digitalization of activities}

To identify a method to be used to assess the degree of digitalization of the four selected activities, we started with answering the following questions: (1) how is technology used to 
carry out a construction site activity and (2) which data management processes are used to carry out the activity. To address these questions, we relied on the terminology and ideas proposed in previous assessment models. Xie et al. (2011) proposed a progress monitoring system and describe technology use for monitoring, collecting, analyzing, and reporting data. Kim et al. (2013) refer to three steps involved in developing a mobile system for on-site construction management: site monitoring, task management and information sharing. Shirowzhan et al. (2020) consider the data management process to include data acquisition, data transmission, data storage, data processing, data fusion, and computation, visualization and dashboarding. We concluded that the data management processes related to a construction site activity included (1) data acquisition (collection), (2) data entry, (3) data analysis (including data storage, process and computation) and (4) reporting (including dashboarding).

We next try to assess the degree of digitalization of these processes. O'Connor et al. (1999) developed automation and integration measures based on three levels of technology use defined as level 1 no electronic tools used to complete a work function, level 2 some use of electronic tools and level 3 fully automated system to complete the work function. Yang (2008) adds another level related to assessing the degree of automation by splitting level 2 into (i) use of a few somewhat uncommon electronic or mechanized tools and (ii) use of several specialized electronic or mechanized tools. The scale proposed by Kang et al. (2008) relies on the categories of "automation technology" and "integration technology" each assessed on five levels. Boute and Van Mieghem (2020) identify four categories, (1) digital, (2) automated, (3) smart and (4) automated and smart to describe levels for digitalization, automation, and smartness. Their levels for automation are based on no automation (no machine or bot), automation with human control/supervision, automation with conditional autonomous control, automation with autonomous control in certain environments and automation with full autonomy. Their smart category includes: no feedback-control, explicit instructions contingent on one feature, explicit 
instructions contingent on multiple features and machine learning. Thus, previous research bases these levels on a scale from manual operation (no digitalization) to full autonomy using machines.

Therefore, we assess the digitalization of each activity on three levels for the four data management processes: acquisition, entry, analysis and reporting, as Level 1 analogue and manual, Level 2 digital and manual and Level 3 digital and automated (see Table 4).

Table 4. Assessment of digitalization of identified construction activities.

$<$ Insert Table 4 here $>$

\section{Digitalization index}

To accurately assess the degree of digitalization requires consideration of the frequency of the data management process (acquisition, entry, analysis and reporting) and the degree of digitalization of the construction project. These data management processes may be carried out at different degrees of digitalization and different frequencies such as often at level 3 and rarely at level 1. Previous studies rely on a 5-point-Likert scale to assess frequency of IT use, ranging from never to always (Koekemoer and Smallwood 2007), frequency of ICT use ranging from never to very often (daily) (Isaksson et al. 2009), frequency of BIM use on a scale ranging from never, to occasionally to often (Eadie et al. 2013), and frequency of hardware use on a scale ranging from never to always (Sezer and Bröchner 2019). These studies compare usage among different groups and identify the most frequently used hardware. However, our objective is to determine the frequency and degree of digitalization of a data management process, meaning that responses related to frequency should sum to $100 \%$. To make the assessment simple and not too time consuming, we used a 5-point-Likert scale ranging from 1 (1-20\% of the time) to $5(81-100 \%$ of the time $)$. 
Therefore, the degree of digitalization of the data management processes (DDDMP) of a particular construction activity $i$ ( $m$ number of activities in total) is determined by the degree of digitalization (D, Level 1-3) and frequency (f, 1-5) of the data management process $j$ (4 in total), see equation (2).

$$
D D D M P_{i, j}=D_{i, j} \cdot f_{i, j} \quad \forall i=1, \ldots, m \text { and } j=1, \ldots, 4
$$

The degree of digitalization of a construction activity (DDCA) $i$ (identified as useful, easy, pressurized, and facilitated to be digitalized) is therefore the sum of the four DDDMPs, as in equation (3).

$$
D D C A_{i}=\sum_{j=1}^{4} D D D M P_{i, j} \quad \forall i=1, \ldots, m
$$

The project digitalization index then is the sum of the DDCA for each construction activity $(i)$ identified as useful, easy, pressurized, and facilitated to be digitalized. This is captured in equation (4).

$$
\text { Digitalization index }=\sum_{i=1}^{m} D D C A_{i}
$$

This can be simplified into equation (5).

$$
\text { Digitalization index }=\sum_{i=1}^{m} \sum_{j=1}^{4} D_{i, j} \cdot f_{i, j}
$$

Based on the index, construction projects can score on a scale starting from completely "analogue and manual" (80), a blend of "analogue and manual" and "digital and manual" (120), completely "digital and manual" (160), a blend of "digital and manual" and "digital and automated" (200) and finally completely "digital and automated" (240). 
For easier interpretation, the index can be normalized into a scale of $1-100$, by relying on the maximum value, see equation (6).

$$
\text { Normalized digitalization index }=\frac{100}{240} \cdot \sum_{i=1}^{m} \sum_{j=1}^{4} D_{i, j} \cdot f_{i, j}
$$

\section{Model for assessing the degree of digitalization of construction projects}

Figure 1 depicts the model assessing the degree of digitalization of construction projects. It starts by identifying which construction activities should be assessed. This is based on the UTAUT filter for the activity, meaning that activity should be useful, easy, have pressure, and have potential to be digitalized. The assessment starts by assessing the data management process (acquisition, entry, analysis, and reporting) based on the criteria of being analogue and manual, digital and manual and digital and automated for each construction activity. The last step involves calculating the project's digitalization index, based on frequency of the degree of digitalization.

Figure 1. Model for assessing degree of digitalization of construction projects.

\section{$<$ Insert Figure 1 here $>$}

\section{Validation of the model and the index}

In order to validate the model and the index, a questionnaire was designed and sent to a site manager from one of the largest contractors in Sweden. The questionnaire was designed to apply the digitalization index on the last construction project of the site manager and therefore asked the degree of digitalization and frequency of data management processes (acquisition, entry, analysis and reporting) for four activities (visualization and 3-D modeling on sites, updating drawings, models and system documents, creating and updating work disposition plans and, updating time and resource plans), including a total of 16 questions. The project was 
a large, new construction project with a contract sum over MSEK 250 (c. USD 29,000,000) and site manager was male and in mid 40 s.

Based on the responses from the site manager, the project's digitalization index was calculated. First the degree of digitalization of the data management processes were calculated (see equation (2)). The site manager combined different frequencies with different degrees of digitalization, for instance for visualization of drawings and 3-D models, the site manager reported that they collect data with (i) manual inspections $41-60 \%$ of the time, (ii) digitized inspections requiring user interpretation $1-20 \%$ of the time and (iii) digitized inspections with no requirement of user interpretation $1-20 \%$ of the time. Based on this, degree of digitalization of data acquisition process for visualization of drawings and 3-D models (DDDMP $\left.{ }_{\mathrm{d}, \mathrm{v}}\right)$ was calculated as:

$$
D D D M P_{d, v}=(1 \cdot 3)+(2 * 1)+(3 * 1)=8
$$

The same equation was used for calculating the degree of digitalization for data entry (5), analysis (8) and reporting (8). Second, the degree of digitalization of visualization of drawings and 3-D models $\left(\mathrm{DDCA}_{\mathrm{v}}\right)$ was calculated by summing degree of digitalization of four data management processes (see equation (3)).

$$
D D C A_{v}=8+5+8+8=29
$$

By applying the same equation, degree of digitalization of updating drawings, models and system documents (32), creating and updating work disposition plans (36) and, updating time and resource plans (37) were calculated. Third, the degree of digitalization of the project was calculated by summing the degree of digitalization of four activities (see equation (4)).

$$
\text { Digitalization index }=29+32+36+37=134
$$


Two days later, a semi-structured interview was done with the same site manager which lasted around 30 minutes to investigate (i) whether the index was accurately reflecting the degree of digitalization of the construction project and (ii) whether there were any technical difficulties, misunderstandings, or suggestions for improving the assessment. In the beginning of the interview, the site manager was asked to describe the construction project's degree of digitalization and the site manager stated: "in this project, we do not have those traditional paper-based drawings, we collect everything including drawings and details we need from computers. We go in models and such, check them and then we print them out on paper. We are more digitalized than paper-based. But we do not have any automation in this project". Following that, the digitalization index of the project (134) was shown to the site manager on the scale starting from completely "analogue and manual" (80), a blend of "analogue and manual" and "digital and manual" (120), completely "digital and manual" (160), a blend of "digital and manual" and "digital and automated" (200) and finally completely "digital and automated" (240). The site manager agreed that the project was located accurately, being close to a blend of "analogue and manual" and "digital and manual". When it comes to technical aspects, the site manager mentioned that it would be easier if the questionnaire automatically summed up the frequencies to $100 \%$ or reminded that the sum of the frequencies should be $100 \%$. No recommendations for improvement were given by the site manager who acknowledged that the measurement was easy and took only 6 minutes to fill in the questionnaire.

\section{Conclusions}

The construction industry is in an era of digitalization but despite efforts to introduce new technologies, it is one of the least digitally advanced industries. The construction industry is project based but we know little about how much construction projects are digitalized. This paper developed a digitalization index to assess degree of digitalization of construction projects. 
Previous examples such as technology use and integration (TUI) index and automation and integration scales had two main problems: (i) they require assessment of degree of technology use for more than 50 activities which is cumbersome and (ii) assessments are done rather abstract, meaning that respondents were asked to report their degree of technology use for an activity where data processes (such as inputting, analyzing and reporting data) and frequency tend to be overlooked. Unlike previous examples, the digitalization index developed in this paper requires assessment of degree of digitalization for only four activities, which lasts around 5-6 minutes. To keep the assessment simple and not too time consuming for site managers, four activities were identified, based on the responses to a questionnaire drawing on the UTAUT. These activities were, (i) visualization and 3-D modeling on sites, (ii) updating drawings, models and system documents, (ii) creating and updating work disposition plans and, (iv) updating time and resource plans. The proposed digitalization index was built based on the degree of digitalization of the data management processes, leading to a more comprehensive assessment, involved in these four activities.

The theoretical contribution of this paper is twofold. First, it contributes by using UTAUT as a filter to reduce construction site activities to assessment of the degree of digitalization of construction projects and benchmarking among projects. This approach could be applied to other project-based industries where an initial list of activities needs to be defined and then reduced. Second, it provides insights into how digitalization of construction projects can be assessed. Previous models have focused on assessing digitalization trends at the wider industry level. However, it is equally important to assess digitalization trends at the project level. This paper contributes by proposing a model which shifts the focus from the industry to the project level. The digitalization index can help to identify the low scoring projects and these projects can be studied as case studies to explain why their scores are low. 
This project-centered assessment also contributes to practice. The digitalization index for projects will allow a benchmarking among projects to highlight why some projects score better in terms of digitalization and the problems related to lower levels of digitalization. Furthermore, linking level of technology use to project performance has been a popular subject in previous studies (e.g. O'Connor and Yang 2004). Therefore, an accurate digitalization index will improve identification of associations between digitalization and project performance including productivity, and environmental and safety performance through questionnaires. Applying the digitalization index to longitudinal data will allow observation of digitalization trends in the construction industry.

The study has two limitations. First, the study is based on Swedish site managers. Future research can replicate the model and the UTAUT questionnaire for an international comparison, to show whether the same four activities are the highest ranked among site managers. Second, the index is developed for on-going and completed construction projects and it was validated in one, almost completed construction project. The digitalization index can be used for upcoming projects by asking site managers the planned degree of digitalization and frequency of data management processes (acquisition, entry, analysis and reporting) for four activities (visualization and 3-D modeling on sites, updating drawings, models and system documents, creating and updating work disposition plans and, updating time and resource plans). Before applying the digitalization index via an industry wide questionnaire, future studies are recommended to validate and pretest the index in several projects which can include suitability of the index for upcoming projects.

\section{Data availability statement}

Some or all data, models, or code that support the findings of this study are available from the corresponding author upon reasonable request. 


\section{Acknowledgements}

The authors acknowledge financial support from the strategic innovation program 'Smart Built Environment', funded by Vinnova (Swedish Governmental Agency for Innovation Systems),

Formas (Swedish Government Research Council for Sustainable Development), and Energimyndigheten (Swedish Energy Agency).

\section{References}

Ahmad, Z., Thaheem, M. J., and Maqsoom, A. (2018). "Building information modeling as a risk transformer: An evolutionary insight into the project uncertainty." Autom. Constr., 92, 103119.

Ahuja, V., Yang, J., and Shankar, R. (2010). "IT-enhanced communication protocols for building project management." Eng. Constr. Archit. Manag., 17(2), 159-179.

Al Qady, M., and Kandil, A. (2014). "Automatic clustering of construction project documents based on textual similarity." Autom. Constr., 42, 36-49.

Atkin, B., Clark, A., Smith, D., and Excellence, C. I. C. o. (1996). "Benchmarking Best Practice Report: Construction Site Processes." Construct IT Centre of Excellence, Salford.

Blanco, J. L., Mullin, A., Pandya, K., and Sridhar, M. (2017). "The new age of engineering and construction technology." McKinsey \& Company.

Boute, R. N., and Van Mieghem, J. A. (2020). "Digital Operations: Autonomous Automation and the Smart Execution of Work." https://ssrn.com/abstract=3400186. (Accessed 16 November 2020). 
Byggfakta (2018). https://byggfakta.today/byggfakta-listar-de-storsta-

byggnadsentreprenorerna- 2018-131226/nyhet.html (Accessed 7 April 2021).

Catlin, T., Scanlan, J., and Willmott, P. (2015). "Raising your digital quotient." McKinsey Quarterly, 1.

Chalker, M., and Loosemore, M. (2016). "Trust and productivity in Australian construction projects: a subcontractor perspective." Eng. Constr. Archit. Manag., 23(2), 192-210.

Cheng, T., Teizer, J., Migliaccio, G. C., and Gatti, U. C. (2013). "Automated task-level activity analysis through fusion of real time location sensors and worker's thoracic posture data." Autom. Constr., 29, 24-39.

Eadie, R., Browne, M., Odeyinka, H., McKeown, C., and McNiff, S. (2013). "BIM implementation throughout the UK construction project lifecycle: An analysis." Autom. Constr., 36, 145-151. El-Mashaleh, M. S. (2007). "Benchmarking information technology utilization in the construction industry in Jordan." J. Inf. Technol. Constr., 12(19), 279-291.

Gaith, F. H., Khalim, A., and Ismail, A. (2009). "Usage of information technology in construction firms; Malaysian construction industry." Eur. J. Sci. Res., 28(3), 412-421.

Gandhi, P., Khanna, S., and Ramaswamy, S. (2016). "Which industries are the most digital (and why)." Harv. Bus. Rev., 1.

Getuli, V., Capone, P., Bruttini, A., and Isaac, S. (2020). "BIM-based immersive Virtual Reality for construction workspace planning: A safety-oriented approach." Autom. Constr., 114, 103160.

Gruszka, A., Jupp, J., and De Valence, G. (2017). "Digital Foundations: How Technology is Transforming Australia's Construction Sector." 
Hasan, A., Baroudi, B., Elmualim, A., and Rameezdeen, R. (2018). "Factors affecting construction productivity: a 30 year systematic review." Eng. Constr. Archit. Manag., 25(7), 916-937.

Hewage, K. N., Ruwanpura, J. Y., and Jergeas, G. F. (2008). "IT usage in Alberta's building construction projects: Current status and challenges." Autom. Constr., 17(8), 940-947.

Hinkka, V., and Tätilä, J. (2013). "RFID tracking implementation model for the technical trade and construction supply chains." Autom. Constr., 35, 405-414.

Hu, X., Rousseau, R., and Chen, J. (2011). "On the definition of forward and backward citation generations." J. Informetr., 5(1), 27-36.

Ibem, E. O., and Laryea, S. (2014). "Survey of digital technologies in procurement of construction projects." Autom. Constr., 46, 11-21.

Isaksson, A., Linde, A., and Vanyushyn, V. (2009). "Environmental management in construction companies: Decisions, technologies and effects." Proc. 5th Nordic Conference on Construction Economics and Organization, 193-204.

Jeelani, I., Han, K., and Albert, A. (2018). "Automating and scaling personalized safety training using eye-tracking data." Autom. Constr., 93, 63-77.

Kang, Y., O’Brien, W. J., Thomas, S., and Chapman, R. E. (2008). "Impact of information technologies on performance: cross study comparison." J. Constr. Eng. Manag., 134(11), 852863.

Kim, C., Park, T., Lim, H., and Kim, H. (2013). "On-site construction management using mobile computing technology." Autom. Constr., 35, 415-423.

Kim, Y. S., Oh, S. W., Cho, Y. K., and Seo, J. W. (2008). "A PDA and wireless web-integrated system for quality inspection and defect management of apartment housing projects." Autom. Constr., 17(2), 163-179. 
Kimoto, K., Endo, K., Iwashita, S., and Fujiwara, M. (2005). "The application of PDA as mobile computing system on construction management." Autom. Constr., 14(4), 500-511.

Koekemoer, V., and Smallwood, J. (2007). "Information Technology (IT) in the construction process." Proc. Association of Researchers in Construction Management (ARCOM) conference, 503-512.

Kubicki, S., and Boton, C. (2014). "IT Barometer Survey in Luxembourg: First results to understand IT innovation in Construction sector." Comput. Civ. Eng., 179-186.

Kubicki, S., Guerriero, A., Schwartz, L., Daher, E., and Idris, B. (2019). "Assessment of synchronous interactive devices for BIM project coordination: Prospective ergonomics approach." Autom. Constr., 101, 160-178.

Letsbuild (2020). https://www.letsbuild.com/ (Accessed 20 October, 2020).

Li, H., Chan, G., and Skitmore, M. (2012). "Multiuser virtual safety training system for tower crane dismantlement." J. Comput. Civ. Eng., 26(5), 638-647.

Li, X., Yi, W., Chi, H.-L., Wang, X., and Chan, A. P. C. (2018). "A critical review of virtual and augmented reality (VR/AR) applications in construction safety." Autom. Constr., 86, 150-162. Liang, X., Lu, M., and Zhang, J.-P. (2011). "On-site visualization of building component erection enabled by integration of four-dimensional modeling and automated surveying." Autom. Constr., 20(3), 236-246.

Love, P. E. D., Zhou, J., and Matthews, J. (2016). "Systems information modeling: From file exchanges to model sharing for electrical instrumentation and control systems." Autom. Constr., 67, 48-59.

Luo, X., Li, H., Wang, H., Wu, Z., Dai, F., and Cao, D. (2019). "Vision-based detection and visualization of dynamic workspaces." Autom. Constr., 104, 1-13. 
Matthews, J., Love, P. E. D., Heinemann, S., Chandler, R., Rumsey, C., and Olatunj, O. (2015). "Real time progress management: Re-engineering processes for cloud-based BIM in construction." Autom. Constr., 58, 38-47.

Nourbakhsh, M., Zin, R. M., Irizarry, J., Zolfagharian, S., and Gheisari, M. (2012). "Comparing information technology adoption between developing and developed countries." Construction Research Congress: Construction Challenges in a Flat World, 650-657.

Nourbakhsh, M., Zin, R. M., Irizarry, J., Zolfagharian, S., and Gheisari, M. (2012). "Mobile application prototype for on-site information management in construction industry." Eng. Constr. Archit. Manag., 19(5), 474-494.

O'Connor, J. T., Kumashiro, M. E., and Welch, K. A. (1999). "Measuring automation and integration in the construction industry." ISARC'99: International symposium on automation and robotics in construction, Madrid, 211-216.

O'Connor, J. T., and Yang, L.-R. (2004). " Project performance versus use of technologies at project and phase levels." J. Constr. Eng. Manag., 130(3), 322-329.

Pett, M. A. (2015). Nonparametric statistics for health care research: Statistics for small samples and unusual distributions, Sage Publications, London.

Razavi, S. N., and Haas, C. T. (2010). "Multisensor data fusion for on-site materials tracking in construction." Autom. Constr., 19(8), 1037-1046.

Samuelson, O. (2002). "IT-Barometer 2000-The use of IT in the Nordic construction industry." J. Inf. Technol. Constr., 7(1), 1-26.

Samuelson, O. (2008). "The IT-barometer-A decade's development of IT use in the Swedish construction sector." J. Inf. Technol. Constr., 13, 1-19.

Samuelson, O., and Björk, B.-C. (2014). "A longitudinal study of the adoption of IT technology in the Swedish building sector." Autom. Constr., 37, 182-190. 
Santos, R., Costa, A. A., Silvestre, J. D., and Pyl, L. (2019). "Informetric analysis and review of literature on the role of BIM in sustainable construction." Autom. Constr., 103, 221-234.

Sarshar, M., and Isikdag, U. (2004). "A survey of ICT use in the Turkish construction industry." Eng. Constr. Archit. Manag., 11(4), 238-247.

Schober, K.-S., Hoff, P., and Sold, K. (2016). "Digitization in the construction industry: Building Europe's road to "Construction 4.0"." Think Act.

Serpell, A., Barai, S., and Oladapo, A. A. (2005). "An investigation into the use of ICT in the Nigerian construction industry." J. Inf. Technol. Constr., 12, 261-277.

Sezer, A. A., and Bröchner, J. (2019). "Site managers' ICT tools for monitoring resources in refurbishment." Eng. Constr. Archit. Manag., 27(1), 109-127.

Shirowzhan, S., Tan, W., and Sepasgozar, S. M. (2020). "Digital Twin and CyberGIS for Improving Connectivity and Measuring the Impact of Infrastructure Construction Planning in Smart Cities." ISPRS Int. J. Geo-Inf., 9, 240.

Shrestha, P. P., Shields, D. R., Oparaugo, D. A., and Pradhananga, N. (2011). "Comparative study of information technology use by architects, engineers and contractors." J. Civ. Eng. Archit., 5(5).

Sykes, C. (2018). "Smarter construction, stronger economy, inclusive society: The European construction industry manifesto for digitalisation." https://ebc-construction.eu/wpcontent/uploads/Construction industry manifesto on digitalisation _ FINAL WEB.pdf

(Accessed 20 October, 2020).

Tam, V. W., Tam, C.-M., Yiu, K. T., and Cheung, S.-O. (2006). "Critical factors for environmental performance assessment (EPA) in the Hong Kong construction industry." Constr. Manag. Econ., 24(11), 1113-1123. 
Venkatesh, V., Morris, M. G., Davis, G. B., and Davis, F. D. (2003). "User acceptance of information technology: Toward a unified view." MIS quarterly, 425-478.

Wang, L.-C. (2008). "Enhancing construction quality inspection and management using RFID technology." Autom. Constr., 17(4), 467-479.

Xie, H., Fernando, S., and AbouRizk, S. (2011). "Integrating realtime project progress input into a construction simulation model." Proc. Winter Simulation Conference (WSC), IEEE, Phoenix, USA, 3443-3454.

Yang, L.-R. (2008). "Exploring the links between task-level automation usage and project satisfaction." Autom. Constr., 17(4), 450-458.

Yang, L.-R., Chen, J.-H., and Wang, H.-W. (2012). "Assessing impacts of information technology on project success through knowledge management practice." Autom. Constr., 22, 182-191. Yang, L.-R., and O'Connor, J. T. (2005). "Associations of Technology Utilization with Project Stakeholder Success." Comput. Civ. Eng., 1-6.

Yang, L.-R., O'Connor, J. T., and Huang, C.-F. (2007). "Comparison of technology utilization and benefits in Taiwanese and US industries." J. Manag. Eng., 23(3), 147-155.

Yang, L.-R., O'Connor, J. T., and Wang, C.-C. (2006). "Technology utilization on different sizes of projects and associated impacts on composite project success." Int. J. Proj. Manag., 24(2), 96-105.

Zhou, W., Whyte, J., and Sacks, R. (2012). "Construction safety and digital design: A review." Autom. Constr., 22, 102-111. 
Table 1. Respondent demographics.

\begin{tabular}{llllll}
\hline Gender & Male & Female & & & \\
& $103(91 \%)$ & $10(9 \%)$ & & & \\
\hline Age & $\leq 30$ years & $31-40$ & $41-50$ & $51-60$ & $\geq 61$ years \\
& & years & years & years & \\
& $21(18 \%)$ & $34(30 \%)$ & $28(25 \%)$ & $27(24 \%)$ & $3(3 \%)$ \\
\hline Years of experience & $\leq 2$ years & $3-10$ years & $\geq 10$ years & & \\
& $0(0 \%)$ & $23(20 \%)$ & $90(80 \%)$ & \\
\hline Project type & New & Renovation & & \\
& construction & & & \\
& $90(80 \%)$ & $23(20 \%)$ & & \\
\hline Size of company & Large & SME & & \\
& $94(83 \%)$ & $19(17 \%)$ & & \\
\end{tabular}


Table 2. Gross list of potential activities to digitalize.

\begin{tabular}{|c|c|}
\hline Activities & Source from literature \\
\hline Collect, update and save all project documents & Al Qady and Kandil (2014); Blanco et al. (2017) \\
\hline $\begin{array}{l}\text { Create and report on the environmental impact } \\
\text { of the construction project }\end{array}$ & Kimoto et al. (2005); Tam et al. (2006) \\
\hline Create and update work disposition plans & Getuli et al. (2020); Luo et al. (2019) \\
\hline Create material quantity lists & Love et al. (2016); Nourbakhsh et al. (2012) \\
\hline Create, prioritize and assign tasks to craftsmen & Blanco et al. (2017); Nourbakhsh et al. (2012) \\
\hline $\begin{array}{l}\text { Delivery monitoring and handling of delivery } \\
\text { notes }\end{array}$ & $\begin{array}{l}\text { Atkin et al. (1996); Blanco et al. (2017); Hinkka } \\
\text { and Tätilä (2013); Nourbakhsh et al. (2012) }\end{array}$ \\
\hline $\begin{array}{l}\text { Ensure that craftsmen in the project have the } \\
\text { right expertise }\end{array}$ & Li et al. (2012); Nourbakhsh et al. (2012) \\
\hline $\begin{array}{l}\text { Follow up and improve energy consumption } \\
\text { during the project }\end{array}$ & Santos et al. (2019); Tam et al. (2006) \\
\hline $\begin{array}{l}\text { Follow up and improve waste management } \\
\text { during the project }\end{array}$ & $\begin{array}{l}\text { Santos et al. (2019); Sezer and Bröchner (2019); } \\
\text { Tam et al. (2006) }\end{array}$ \\
\hline $\begin{array}{l}\text { Follow up the presence of staff and visitors and } \\
\text { the use of protective equipment }\end{array}$ & Atkin et al. (1996); Nourbakhsh et al. (2012) \\
\hline Follow-up and management of deviations & $\begin{array}{l}\text { Atkin et al. (1996); Blanco et al. (2017); } \\
\text { Nourbakhsh et al. (2012) }\end{array}$ \\
\hline Follow-up of working hours for craftsmen & $\begin{array}{l}\text { Blanco et al. (2017); Cheng et al. (2013); } \\
\text { Nourbakhsh et al. (2012); Sezer and Bröchner } \\
\text { (2019) }\end{array}$ \\
\hline $\begin{array}{l}\text { Implement problem solving at the construction } \\
\text { site and communicate these }\end{array}$ & $\begin{array}{l}\text { Nourbakhsh et al. (2012); Sezer and Bröchner } \\
\text { (2019) }\end{array}$ \\
\hline Keeping site diaries & $\begin{array}{l}\text { Atkin et al. (1996); Nourbakhsh et al. (2012); } \\
\text { Sezer and Bröchner (2019) }\end{array}$ \\
\hline $\begin{array}{l}\text { Monitoring and control of the progress of the } \\
\text { project }\end{array}$ & $\begin{array}{l}\text { Blanco et al. (2017); Kimoto et al. (2005); } \\
\text { Matthews et al. (2015); Nourbakhsh et al. (2012) }\end{array}$ \\
\hline Perform and save quality self-checks & $\begin{array}{l}\text { Atkin et al. (1996); Kim et al. (2008); } \\
\text { Nourbakhsh et al. (2012); Wang (2008) }\end{array}$ \\
\hline Purchase of materials and services & $\begin{array}{l}\text { Atkin et al. (1996); Hinkka and Tätilä (2013); } \\
\text { Nourbakhsh et al. (2012) }\end{array}$ \\
\hline Safety information and training for staff & $\begin{array}{l}\text { Atkin et al. (1996); Blanco et al. (2017); Jeelani } \\
\text { et al. (2018); Kimoto et al. (2005); Li et al. } \\
\text { (2018); Zhou et al. (2012) }\end{array}$ \\
\hline
\end{tabular}


Share information between construction projects and companies

Track and report incidents and accidents

Track materials and equipment at the construction site

Tracking subcontractors' progress and payments

Update and follow up on contract compliance with suppliers and subcontractors

Update and follow up on contract compliance, including contract changes/variations, with the client

Update drawings, models and system documents

Update of time and resource plans

Visualize drawings and 3-D models on site
Blanco et al. (2017); Nourbakhsh et al. (2012); Yang et al. (2012)

Blanco et al. (2017); Li et al. (2018);

Nourbakhsh et al. (2012)

Blanco et al. (2017); Nourbakhsh et al. (2012); Razavi and Haas (2010)

Atkin et al. (1996); Nourbakhsh et al. (2012)

Blanco et al. (2017); Ibem and Laryea (2014)

Blanco et al. (2017); Ibem and Laryea (2014)

Blanco et al. (2017); Kimoto et al. (2005)

Atkin et al. (1996); Matthews et al. (2015); Nourbakhsh et al. (2012); Sezer and Bröchner (2019)

Blanco et al. (2017); Liang et al. (2011) 
Table 3. Normalized sum of ranks of 27 activities ( $U=$ usefulness, $E=$ ease of use, $P=$ peer pressure and $\mathrm{C}=$ facilitating conditions).

\begin{tabular}{|c|c|c|c|c|c|c|}
\hline Activities & $\mathbf{U}$ & $\mathbf{E}$ & $\mathbf{P}$ & $\mathbf{C}$ & Total & Rank \\
\hline Visualize drawings and 3-D models on site & 283 & 206 & 230 & 260 & 979 & 1 \\
\hline Update drawings, models and system documents & 148 & 160 & 170 & 187 & 664 & 2 \\
\hline Update of time and resource plans & 158 & 109 & 136 & 150 & 553 & 3 \\
\hline Create and update work disposition plans & 118 & 192 & 61 & 173 & 543 & 4 \\
\hline Keeping site diaries & 31 & 216 & 61 & 99 & 407 & 5 \\
\hline Collect, update and save all project documents & 97 & 91 & 83 & 68 & 339 & 6 \\
\hline $\begin{array}{l}\text { Update and follow up on contract compliance, } \\
\text { including contract changes/variations, with the client }\end{array}$ & 65 & 44 & 139 & 67 & 314 & 7 \\
\hline Track and report incidents and accidents & 47 & 82 & 100 & 74 & 302 & 8 \\
\hline Follow-up and management of deviations & 55 & 61 & 110 & 74 & 300 & 9 \\
\hline Perform and save quality self-checks & 78 & 41 & 87 & 63 & 269 & 10 \\
\hline Monitoring and control of the progress of the project & 69 & 27 & 82 & 41 & 219 & 11 \\
\hline Follow-up of working hours for craftsmen & 63 & 79 & 24 & 52 & 218 & 12 \\
\hline Purchase of materials and services & 60 & 55 & 51 & 46 & 213 & 13 \\
\hline Create material quantity lists & 60 & 75 & 9 & 67 & 211 & 14 \\
\hline $\begin{array}{l}\text { Track materials and equipment at the construction } \\
\text { site }\end{array}$ & 49 & 20 & 22 & 52 & 142 & 15 \\
\hline Delivery monitoring and handling of delivery notes & 35 & 43 & 23 & 30 & 131 & 16 \\
\hline Safety information and training for staff & 35 & 26 & 23 & 31 & 115 & 17 \\
\hline Create, prioritize and assign tasks to craftsmen & 56 & 12 & 5 & 37 & 110 & 18 \\
\hline $\begin{array}{l}\text { Update and follow up on contract compliance with } \\
\text { suppliers and subcontractors }\end{array}$ & 30 & 14 & 55 & 11 & 110 & 19 \\
\hline $\begin{array}{l}\text { Share information between construction projects and } \\
\text { companies }\end{array}$ & 23 & 21 & 26 & 27 & 97 & 20 \\
\hline $\begin{array}{l}\text { Ensure that craftsmen in the project have the right } \\
\text { expertise }\end{array}$ & 18 & 39 & 28 & 10 & 95 & 21 \\
\hline $\begin{array}{l}\text { Follow up and improve waste management during } \\
\text { the project }\end{array}$ & 11 & 45 & 13 & 12 & 82 & 22 \\
\hline Tracking subcontractors' progress and payments & 27 & 11 & 38 & 1 & 77 & 23 \\
\hline
\end{tabular}




\begin{tabular}{llllllll}
\hline $\begin{array}{l}\text { Create and report on the environmental impact of the } \\
\text { construction project }\end{array}$ & 1 & 48 & 19 & 76 & 24 \\
$\begin{array}{l}\text { Implement problem solving at the construction site } \\
\text { and communicate these }\end{array}$ & 35 & 0 & 17 & 20 & 73 & 25 \\
$\begin{array}{l}\text { Follow up the presence of staff and visitors and the } \\
\text { use of protective equipment }\end{array}$ & 7 & 23 & 26 & 14 & 70 & 26 \\
$\begin{array}{l}\text { Follow up and improve energy consumption during } \\
\text { the project }\end{array}$ & 0 & 0 & 22 & 12 & 34 & 27 \\
\hline
\end{tabular}


Table 4. Assessment of digitalization of identified construction activities.

\begin{tabular}{lllll}
\hline $\begin{array}{l}\text { Degree of } \\
\text { digitalization }\end{array}$ & Data acquisition & Data entry & Analysis & Reporting \\
\hline Level 1 & Manual inspections & On paper & On paper & On paper \\
Level 2 & $\begin{array}{l}\text { Digitized } \\
\text { inspections } \\
\text { requiring user } \\
\text { interpretation }\end{array}$ & $\begin{array}{l}\text { Digitized } \\
\text { manually }\end{array}$ & $\begin{array}{l}\text { Manually with } \\
\text { software }\end{array}$ & $\begin{array}{l}\text { Digitalized but } \\
\text { manually } \\
\text { distributed }\end{array}$ \\
& $\begin{array}{l}\text { Digitized } \\
\text { inspections with no } \\
\text { requirement of user } 3 \\
\text { interpretation }\end{array}$ & $\begin{array}{l}\text { Digitized } \\
\text { automatically }\end{array}$ & $\begin{array}{l}\text { Automatically } \\
\text { with software }\end{array}$ & Automated \\
& & & & \\
\hline
\end{tabular}


1. Identify Construction Activities

- Useful to digitalize

- Easy to digitalize

- Pressure to digitalize

- Facilitating conditions exist

\section{Data}

Management

Processes

Data Acquisition

- Data Entry

- Data Analysis

- Data Reporting

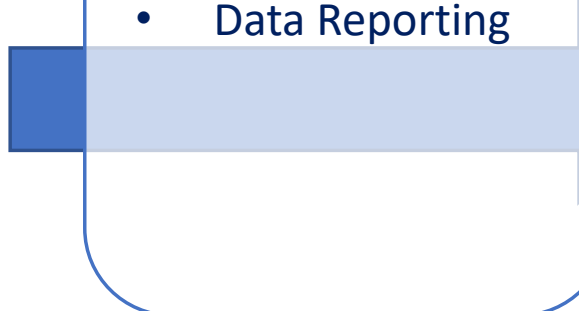

2. Identify Degree of Digitalization

1. Analogue and manually

2. Digital and manually

3. Digital and automated

\section{Calculate Digitalization Index}

- Frequency

- Degree of digitalization of data management processes

- Degree of digitalization of construction of activities

- Digitalization index 